\title{
New sources of earliness for Finnish faba bean breeding
}

\author{
Hamid Khazaei ${ }^{1 *}$, Frederick Stoddard ${ }^{1}$, Clara Lizarazo ${ }^{1}$ and Ken Street ${ }^{2}$ \\ ${ }^{1}$ Department of Agricultural Sciences, P O Box 27 (Latokartanonkaari 5), University of Helsinki, FIN- \\ 00014 , Finland \\ ${ }^{2}$ ICARDA, P.O. Box 5466, Aleppo, Syrian Arab Republic \\ "Corresponding author: hamid.khazaei@ helsinki.fi
}

\begin{abstract}
Crop yields in Finland are limited by many factors, such as the short growing season and spring drought. Thus earliness is an important breeding goal in Finnish agriculture, and is especially needed in some crops such as faba bean that have a longer growing period than cereals. During 2009-2011, 400 accessions of faba bean (Vicia faba L.) from 34 countries were evaluated for morphophysiological traits related to drought resistance and the earliest accessions were identified. The four earliest accessions, from Cyprus and Syria, were sown in a pot experiment, together with Kontu and Witkiem Manita (an early-flowering, large-seeded Dutch cultivar) in order to determine days to flowering, podding and maturity under controlled conditions. The experiment was conducted in a randomized complete block design with 3 replicates. There were highly significant differences for all studied traits $(\mathrm{p}<0.001)$. Accessions D497, D557 and D505 had significantly faster progress to flowering and podding compared to Kontu. Accession D497 was the earliest genotype with 947 GDD (Growing degree-days to maturity), followed by accession D557 (985 GDD), and Kontu and Witkiem Manita were latest accessions in this study (1165 and 1159 GDD, respectively). The linkage of early flowering and early maturity to large seed size needs to be tested. These accessions may be valuable sources of earliness that could be used in faba bean breeding for short seasons such as those in Finland.
\end{abstract}

Key words: earliness, faba bean, germplasm, Finland, Vicia faba 


\section{Introduction}

Finland has a short and relatively cool growing season. In addition, spring drought is a normal aspect of the Finnish growing season and summer droughts, such as those of 2006 and 2010, are also well known. Climate change is expected to lead to increased temperatures and altered precipitation patterns in the Nordic region (Stoddard et al., 2011). Earliness is one of the most important plant strategies to escape drought and a key factor in grain legume adaptation to the Nordic region (Stoddard et al., 2009). Furthermore, earliness may protect crops from several different biotic and abiotic stresses such as pests, diseases cold and heat. The available legumes such as faba bean (Vicia faba L.) have a longer growing period than cereals (Stoddard et al., 2009), and many farmers are unfamiliar with legume crops, so Finnish agriculture gains few of the benefits of growing legumes. Faba bean is a valuable break crop in environmentally sustainable arable production systems across Europe and a key input into the animal feed chain.

The first step of breeding faba bean for earliness in Finland was in the 1960s, with the collection of Karelian landraces. Three cultivars, Mikko (1977), Ukko (1984), Kontu (1997), were released by the Hankkija Plant Breeding Institute, combining earliness with an acceptable yield, seed size and effective biological nitrogen fixation (Hovinen, 1982; 1984; 1990). Kontu was derived from the cross ICARDA $536 \times$ Ukko and is among the earliest cultivars in the world (Stoddard and Hämäläinen, 2011). Nevertheless, it is still not early enough for most of the arable zone of Finland, so new sources of earliness are needed. In surveys of imported cultivars, Kontu was the earliest cultivar but was very susceptible to drought (Stoddard et al., 2010a, 2010b). Hence, the objective of this investigation was to search for early and drought-resistant faba bean germplasm.

\section{Materials and methods}

Four hundred accessions of faba bean from 34 different origins (Table 1) were evaluated during 2009 and 2010 for some morpho-physiological traits related to drought stress under controlled conditions.

Table 1. Information on origins and numbers of accessions used for the primary screening.

\begin{tabular}{lc}
\hline Origin & Number \\
\hline China & 80 \\
Syria & 75 \\
Nepal & 54 \\
Cyprus & 32 \\
Bangladesh & 24 \\
Afghanistan & 18 \\
Greece & 11 \\
Morocco, Ethiopia & $10^{*}$ \\
Turkey & 9 \\
Spain, Russia & $8^{*}$ \\
Algeria, Tajikistan & $7^{*}$ \\
Portugal & 6 \\
Italy, Iraq, Georgia, Macedonia, Tunis & $4^{*}$ \\
Bulgaria, Romania & $3^{*}$ \\
Jordan, Libya, Sweden & $2^{*}$ \\
Azerbaijan, France, Iran, Kazakhstan, Kyrgyzstan, Lebanon, Sudan, Oman, & $1^{*}$ \\
Poland & \\
\hline
\end{tabular}

Same number of accessions from each country

Plants were sown in $2 \mathrm{~L}$ plastic pots containing a mixture of sand and peat $(3: 1 \mathrm{v} / \mathrm{v})$ in wellwatered greenhouse conditions in a randomized complete block design with 4 replicates. Soil moisture level was maintained at field capacity with automatic table irrigation for all plants and to be sure that all plants got enough and same amount of water during the experiments. The four earliest accessions (D429, D497, D505 and D557) came from Cyprus and Syria. They were sown in a further pot experiment on 17 April 2011, together with Kontu and Witkiem Manita (an early-flowering, large-seeded Dutch cultivar) in order to determine days to flowering, days to podding and days to maturity under controlled conditions. Plastic pots containing $5 \mathrm{~L}$ of a mixture of peat and sand $(2: 1 \mathrm{v} / \mathrm{v})$ were used for 
this experiment, which was conducted in a randomized complete block design with 3 replicates. For all experiments, seeds were inoculated with Rhizobium leguminosarum (faba bean strain). Photoperiod was adjusted to $14 \mathrm{~h}$ light and $10 \mathrm{~h}$ dark, and the temperature was $20^{\circ} \mathrm{C}$ day $/ 15^{\circ} \mathrm{C}$ night \pm 2 . Photosynthetic photon flux density (PPFD) was about $300 \mu \mathrm{mol} \mathrm{m}^{-2} \mathrm{~s}^{-1}$ at the canopy level. A constant humidity level was maintained $(60 \%)$. The data are presented in growing degree-days (GDD) using $5^{\circ} \mathrm{C}$ base temperature.

\section{Results and discussion}

The four accessions had fewer GDD to podding and maturity than cv. Kontu and Witkiem Manita. In addition, accessions D497, D557 and D505 had significantly faster progress to flowering compared to Kontu and Witkiem Manita (Figure 1). Accession D497 had the fastest progress for all studied traits with 947 GDD to maturity, followed by D557 (985 GDD) and D429 (997 GDD), while cv. Kontu and Witkiem Manita were latest accessions in this study with 1165 and 1159 GDD, respectively. Accession D429 achieved early maturity in the glasshouse in spite of a later onset of flowering than the other three novel accessions. In field conditions, Witkiem Manita required 100 more GDD to maturity than Kontu (Lizarazo and Stoddard, unpublished data, University of Helsinki). These accessions may be valuable sources of earliness that could be used in faba bean breeding in Finland and other regions with short seasons. All four early accessions have large seeds (> $1 \mathrm{~g})$ and the linkage of early flowering and early maturity to large seed size in this germplasm needs to be tested. In addition, novel ways of achieving earliness, such as the terminal-inflorescence mutation $(t i)$, may have more application here than they have achieved elsewhere (Stoddard 2008).

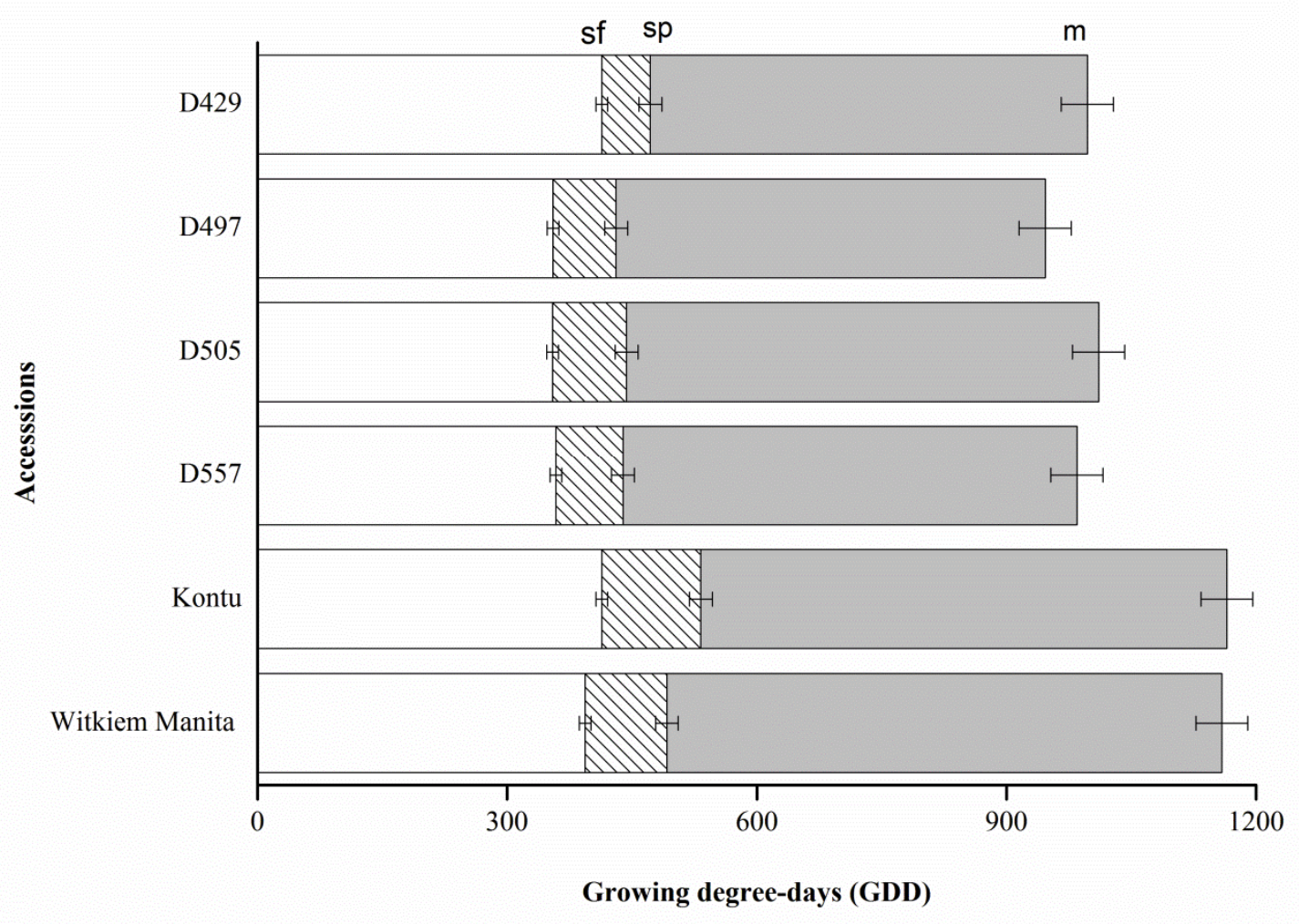

Figure 1. The mean of growing degree-days to flowering, podding and maturity for studied genotypes ( $\mathrm{sf}=\mathrm{GDD}$ to the onset of flowering, $\mathrm{sp}=$ GDD to the onset of podding and $\mathrm{m}=$ GDD to maturity). 


\section{References}

Hovinen, S. 1982. Hankkijan Mikko härkäpapu. Hankkijan kasvinjalostuslaitos tiedote 7:1-20.

Hovinen, S. 1984. Hankkijan Ukko-härkäpapu. Hankkijan kasvinjalostuslaitos tiedote 14:1-12.

Hovinen, S. 1990. Palkoviljat. Hankkijan kasvinjalostuslaitos, Siemenjulkaisu 1990, p. 52-60.

Stoddard, F.L. 2008. New interest in grain legumes in Finland. Second GL-TTP Workshop Integrating Legume Science and Crop Breeding, Novi Sad, Serbia, 27 \& 28 November 2008.

Stoddard, F.L. \& Hämäläinen, K. 2011. Towards the world's earliest maturing faba beans. Grain Legumes 56:9-10.

Stoddard, F.L., Hovinen, S., Kontturi, M., Lindström, K. \& Nykänenk, A. 2009. Legumes in Finnish agriculture: history, present status and future prospects. Agricultural and Food Science 18: 191-205.

Stoddard, F.L., Lizarazo, C.I., Mäkelä, P. \& Nykänen, A. 2010a. New annual legume crops for Finnish conditions. Maataloustieteenpäivät 2010, Viikki, Helsinki, 12 - 13.01.2010, ed. L. Rantamäki-Lahtinen, p. 61. http://www.smts.fi/jul2010/esite2010/052.pdf

Stoddard, F.L., Lizarazo Torres, C.I, Nykänen, A. \& Mäkelä, P. 2010b. Palkoviljoilla rankka kesä. Maaseudun Tiede 67 (4): 14.

Stoddard, F.L., Mäkelä, P. \& Puhakainen, T.A. 2011. Adaptation of boreal field crop production to climate change. Climate Change - Research and Technology for Adaptation and Mitigation. Eds. J. Blanco \& H. Kheradmand. InTech, Croatia. Pp. 403-430. 